2019-12-01

Fibs and fripperies: references to the real in digital illustration

\author{
Black, Stephanie
}

http://hdl.handle.net/10026.1/15282

10.1386/jill_00015_1

Journal of Illustration

Intellect

All content in PEARL is protected by copyright law. Author manuscripts are made available in accordance with publisher policies. Please cite only the published version using the details provided on the item record or document. In the absence of an open licence (e.g. Creative Commons), permissions for further reuse of content should be sought from the publisher or author. 


\section{Stephanie Black}

Plymouth University

Journal of Illustration Volume 6 Number 2

(C) 2019 Intellect Ltd Article. English language. doi: 10.1386/jill_00015_1

\section{Fibs and fripperies: References to the real in digital illustration}

abstract

This article considers the phenomenon of illustrators digitally mimicking traces of the handmade as ornament. It will explore whether these decorative tendencies are Adolf Loos' backward or degenerative tendency, or a generous contribution to our visual environment. It will ask why illustrators falsify the smudges, spills, textures and shadows of paper-based work within the digital workspace, what is gained and lost by doing so, and for whom? These questions will be explored in relation to interviews with two contemporary editorial illustrators and their work, to unpick the professional benefits of the phenome-non, coupled with a foray into theoretical perspectives on ornament. In this regard, the article will consider the benefit of treating ornament as labour, and also whether illustration is suffering from Herbert Read's horror vacui, in order to understand what happens when these terrifying empty spaces within images are filled with introduced artefacts. The discussion will also take skeuomorphism into account to explore the phenomenon, which then raises questions concerning illustration's 'usability'. The article draws upon wildly different perspectives and practices from other fields as it seeks to consider the pleasures and pitfalls of a richly-ornamented composition, and ultimately argues that making 'noise' can be seen as a generous, temporal and critical act.

\section{keywords}

editorial illustration

digital ornament

horror vacui

labour

skeuomorphism

critical practices

\section{introduction}

Contemporary illustrators frequently falsify the smudges, spills, textures and shadows of paper- based work within the digital workspace; using mistakes as compositional elements, and intro- duced visual noise as a component of their picture-making toolkit. This article is concerned with exploring the phenomenon of illustrators digitally mimicking traces of the handmade, and will frame this practise as ornament. The discussion is based on the premise that when illustration is made digitally, such ornament is not the default within the production of the image; it has to be added as a conscious decision on the part of designers. As such, is it decorative ornament, and therefore a pit of savagery and degeneracy as Adolf Loos and Herbert Read propose? This line of enquiry will be pursued in order to explore its counterpoint: the benefit of such additions to the image. The argument that follows will consider examples of work from the two contemporary editorial illustrators (Harry Tennant 
and Tom Jay) interviewed for this article. Their shared use of a handmade aesthetic within digital image-making led to their selection for this article, and their generous insights into their working processes will be woven into an exploration of a slice of the literature on ornament in order to investigate the importance of ornament to its maker. Thereafter, the discussion will be expanded to consider the broader issues arising, concerning labour and the illustrator's responsibility for obsolescence. The article will then proceed to examine the benefit of ornament to the user, and will consider the relevance of the concept of skeuomorphism (mimick- ing real-world objects to explain the function of something on screen) from User Experience Design to do so. In addition, the role of ornament for practitioners seeking to use their practice critically will be considered, and the discussion will conclude with claims as to the generous, temporal and critical potential of 'noisy' illustration.

\section{Making noise: a summary of interviewees' comments}

Figure 1 is a digitally produced editorial illustration by Harry Tennant, demonstrating the visual phenomenon this article is concerned with in its purposefully introduced spatters and speckles. Tennant was selected as an interviewee along with his contemporary Tom Jay, in order to question how and why they introduce visual noise to images. The interviews were two separate telephone conversations of over an hour each, and took place in November 2018. Both interviewees describe their textural additions as an outcome of their working processes, which were derived in both cases from a love of screen printing developed at university. They learned this image-production process in physical form, preparing different aspects of an image (different colours, for example) as different layers, then compiling these to make a final image. Working in such a way is replete with opportuni- ties for unplanned marks to be introduced, given that the process depends upon materials with the potential to behave erratically and substrates with their own textural qualities. Doing so across

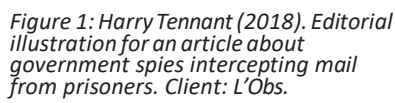

numerous layers multiplies the possibility for making intrusive marks. Both interviewees transported this layered method into the digital workspace when moving from the physical screen to Photoshop, and also transported its resultant aesthetic into the digital realm - in contrast to the default Photoshop canvas onscreen being untroubled by the same analogue textures, and many drawing tools giving the option of making shapes with perfectly clean edges.

Both interviewees emphasized the role of clients in maintaining their printmaking aesthetic in this way, for clients approached them on the basis of existing screenprinted work and sought a reli- able continuation of that visual voice in their portfolios. Tennant and Jay also stated that there was a market for illustration looking like screen printing; its popularity further driving demand for this style. Tennant elaborated on the benefit of working using the process he developed for producing screen-printed images, describing how it made him a more efficient image-maker. He explained how it forces him to do more with less, in that with only two colours as a constraint on the design (as seen in Figure 1) he needs to be more precise with both his concepts and composition to make a successful image. Tennant took both the method and the aesthetic into Photoshop, stating that printmaking was not 
compatible with the speedy turnaround and numerous amendments of commissioned illustration - accessing facilities, preparing and exposing screens before printing an image, then repeating the process when the client requests adjustments is not practically achievable, and has cost implications in relation to the fee for the job. Tennant works digitally immediately after generating ideas on paper, stating that it allows him to spend more time drawing. Tennant explains that by doing so he does not spend his time scanning paper-based drawings and compositing elements on-screen. He adds noise and texture later in the process, which is in contrast to Tom Jay, who works on paper in black and white and uses brushes and other tools to create texture and noise, then scans the component parts in order to compile and colour his images using Photoshop. His method of working in separations also mirrors the screenprinting process, which he finds instructive in providing rules for him to follow at each stage. He argues that working primarily on paper to create each separation allows him to spend less time working on the computer, which he sees as a positive outcome.

\section{labour of love}

Through quizzing my interviewees on their image production processes, it can be seen that the noise within their images is added differently and at different stages. What unites the two is that for both interviewees the aesthetic is a reflection of a working process derived from a handmade process of building images through screenprinting. Both illustrators are making room for processes that privi- lege the handmade within a largely digital workspace. They are both harnessing technology differ- ently to enable them to allocate more time to drawing activity than to image processing, and their attention to the process of making by hand relates to design historian Alice Twemlow's comments on the Arts and Crafts movement in her article 'The decriminalisation of ornament'. Twemlow reminds us of the movement's links between the designer's obsession with handcraft, the social value of this labour and its application to ornament (2005). As Nikolaus Pevsner summarizes, the value of work in terms of reward for the designer and maker was of central importance to the movement's figure- head, William Morris, and resided in the enjoyment of craft. Pevsner traces this line of thought back to Morris's predecessors, the architect and designer Augustus Pugin and art critic John Ruskin: 'Truth in making is to Ruskin making by hand, and making by hand is making with joy' (1960: 23). There are echoes of this ambition in the above comments from both interviewees on their navigation of the digital workspace, in order to rebalance their efforts in favour of the more joyous experience of draw- ing by hand. In their appreciation and acceptance of certain strengths of machine work they diverge from Morris's rejection of mechanized labour (as Pevsner describes it), and in turn resolve the conun- drum it presented to Morris in terms of the increased cost of manufactured items by making their images affordable through efficiency. Although the machine was Morris's 'arch-enemy' according to Pevsner, Morris later exhibited a reluctant acceptance of it as a conduit to better conditions, and this approach is taken up by his follower, C. R. Ashbee in reflection of a shift towards Modernism's embrace of the machine (1960: 24-26). In this respect Jay and Tennant represent the transition having been successful, but their comments on the seemingly competing pressures of efficiency and joy arising from the adoption of machines within the creative process show that there is still progress to be made in order to achieve better conditions. 


\section{criminal damage}

Pevsner quotes Morris's definition of art as 'the expression by man of his pleasure in labour [...] made by the people and for the people, as a happiness for the maker and the user' (1960: 23). Happiness for the maker and user will be explored in turn, to extend the discussion of the social power of labour raised by Twemlow. What is curious about Tennant's work is that the addition of noise through digital means seems to have become separated from the joyous process of drawing, in that satisfaction in drawing could have been achieved without noise, raising the question of who stands to lose if the craft of ornament is removed. This point is addressed in Twemlow's discussion of the production of digital ornament as craft, and the role of the computer as a tool facilitating this. Twemlow quotes Denise Gonzalez Crisp, who suggests that: 'It feels like this powerful tool that allows complexity that only craftspeople value'(emphasis added). This is an intriguing suggestion that digital ornament provides happiness for the maker alone, and overlaps with Adolf Loos' comments on ornament as of value solely to the craftsperson as set out in his 1908 essay Ornament and Crime (republished in Conrads 1971). Loos proposes an anecdote concerning shoemaking to argue that

ornament is labour without adequate remuneration, but (in a reflection of Gonzales Crisp's point) he suggests that despite this, it is of value to the maker deriving satisfaction from their work. As a result of asking his fictional shoemaker to abstain from decorating shoes, Loos states: 'he has less work, but I have taken away all his joy' (Conrads 1971: 22). Whilst aligning Gonzalez Crisp with Loos without the former's consent may be rash (considering that some of his sentiments are indefensible in the modern world) their shared emphasis on value and labour will be pursued here, with Loos' asser- tions having taken on a different tone over the intervening years since publication in relation to designers'responsibility for their output. Loos uses the term'wasted labour power'to describe orna- ment, a term applicable to Tennant's digital noise as it would probably have no immediate utility to Loos, being an addition to the form. Form should be plain and unadorned, if Loos' exacting standards for effective design and the evolution of culture in the modern world are to be met (Pevsner 1960: 30; Conrads 1971: 20).

The intriguing aspect of Loos's diatribe against ornament is his assertion that by selecting the unadorned design, the worker responsible for it regains the time that would have been wasted on decorative details. In contrast, by making the adorned design Tennant has freed his time from a lengthy production process. The technology enabling him to mimic the aesthetic of the handcrafted image enables this reconfiguration of labour time, in keeping with Loos'embrace of the efficiency of the machine. As Pevsner points out, Loos was one of the first generation of designers to 'admire the machine and to understand its essential character and consequences in the relation of architecture and design to ornamentation', and here Tennant shows how the same consequences can be achieved with a different approach to ornament (1960: 27). In their savvy approach to the distribution of labour time amongst the various stages of producing images, Tennant and Jay show a sense of agency that could be exploited further. For example, could adopting Loos' approach and valuing ornament for the labour required to produce it make it useful in addressing the tension between machine and joy, as a continuation of Morris's project? In practical terms, when faced with poor working conditions illustrators might explore withholding their labour, potentially utilizing ornament as a tool for protest. 
In his broad view of the repercussions of wasted labour, Loos brings moral overtones to the discussion. Loos points out the inevitable obsolescence of objects designed with ornament, for they are susceptible to fall out of fashion and be destroyed. He notes that industry embraces such an opportunity to drive greater consumption to generate work and profits. This planned obsolescence is 'psychological obsolescence' as Giles Slade describes in his book Made to Break: Technology and Obsolescence in America, while outlining the numerous and nefarious strategies adopted by designers and manufacturers in order to create profit through waste. Slade uses the example of the 1923 Chevrolet to explain the difference between the use of style in psychological obsolescence to render previous designs extinct as distinct from technological obsolescence, where the technology is superseded (2007: 36). At the time of writing, Loos' concern with longevity is occupying designers and rising in prominence in the mainstream press. An example of this is the high profile and reach of the Ellen MacArthur Foundation's 'A new textiles economy: Redesigning fashion's future' report discussing the textiles system (in particular 'fast fashion') as just one facet of the link between psychological obsolescence and environmental damage (2017). Whilst illustration products - particularly the digital image - may not encounter the circular economy in the same way as the material products of technological obsolescence, the role of ornament as the style Slade sees as complicit within such psychological obsolescence crosses illustration's orbit in the form of surface pattern and packaging. Therefore, as it is one of the elements of a designed object that dates it quickly, ornament then poses an ethical conundrum for makers and teachers of applied illustration and in coming decades may again be written of in terms as charged as those used by Loos. That said, an emphasis on longevity may cut the legs off other areas of illustration such as Jay and Tennant's editorial work, diminishing its political potential.

\section{Falsehoods and flatness}

Jay's Incendiary Policies image (Figure 2) is both ornamented and flat, and potentially able to commu- nicate the same message without the speckled texture added to the sweep of hair. If the texture were to be removed Jay could regain the time he spent creating speckles as Loos suggests, but the ques- tion of what is lost and for whom arises as a counterpoint to the previous paragraphs' emphasis on withholding ornament. The discussion will now consider Jay and Tennant's perspective on the potential loss of the additional noise were it 'withheld' from the viewer.

In this regard I pursued Loos'claim that ornament is wasted time with both interviewees, asking them who it is for, and whether it is time wasted if the viewing public is not made up of the high- minded aesthetes that Loos champions, but rather the heterogenous general public with their range of perspectives on images such as that which usually greets editorial illustration. In response both Jay and Tennant refuted Loos' notion of wasted labour, seeing their ornamentation as a worthwhile act that improves the experience of the viewer. In this respect, making aesthetically satisfying images for their audience can be viewed instead as a generous rather than'degenerate'act, one that does not care to follow Loos'lead in making snobbish distinctions between audience members to define them as'aristocratic'or'cultivated'(or not). When asked about the benefit to the viewer of adding textured marks to his work, Tennant suggests that it can be more effective at attracting attention, saying: 'Illustration that appears to be handmade has something more innately approachable and inviting about it'. Jay suggests that further to this, work with textured 
noise retains the viewer's attention: 'It's more tactile. There's more stuff for the eye to look at, for it to wander around and not be bounced off by flat surfaces [...] hopefully it's more enjoyable for them to look at'.

Figure 2: Tom Jay, Incendiary Policies (2017). Self-initiated work.

Through their comments, both illustrators have raised the following three themes. First, they were concerned with the experience of the viewer. The theme of flat surfaces also arose; the ordered pixels of digitally produced planes of colour appearing to be a smooth counterpoint to the orna- mented, noisy surfaces they were producing. A third theme arising was that of illustration appearing to be handmade, even if it was not. These themes are also the concerns of User Experience Design (UX) discourse, which offers a way of exploring the benefits of this specific kind of ornament - that of mimicking screenprinting in illustration. Because in UX terms, what Harry Tennant is doing is skeuomorphic design in a world of digital illustration capable of absolutely flat design. He is apply-ing texture afterwards (as ornament), it is not part of the process of handcrafting. In their coauthored paper 'A comparative study of skeuomorphic and flat design from a UX perspective', Konstantinos Spiliotopoulos et al. define skeuomorphism: 'In User Interface design, skeuomorphism uses meta- phors of real life and deploys gradients, shadows, ornate details and textures to mimic the real-world object represented'(2018: 1). Their explanation adequately describes Tennant and Jay adding noise as a skeuomorphic reference to screenprints on paper. The authors explain the rationale for mimicking reality: 'Skeuomorphic designs are intended to help users understand how to use a new interface by allowing them to apply their prior knowledge about the real-world objects it contains', which could be interpreted as a further instance of the interviewees' care for the user's experience, specifically regarding the accessibility of images.

What is interesting about Spiliotopoulos et al.'s study on usability is that although they state that

'statistically there is no clear winning approach', flat design was perceived by users (though not proven) to be more usable (2018: 19). They explain this as follows: 'This might be attributed to the simplicity of flat design and to users being overwhelmed with the amount of non-functional orna- ments in the skeuomorphic representation' (Spiliotopoulos et al. 2018: 19). Whereas 'in terms of beauty users seemed to like the skeuomorphic designs' (Spiliotopoulos et al. 2018: 19). This raises questions as to whether these concepts and findings are transferable to illustration, and if so how this might look. The parallels between illustration and UX design explored here show that this avenue of enquiry warrants further attention as concepts from UX design appear to be useful for exploring how the surface of illustration works with its imagery, rather than dividing form from content as can happen within other critical frameworks.

\section{Deceleration}

Adolf Loos' concern with efficiency is a theme echoed here, although taking shape in contradictory fashion. On the one hand, ornament was established as a way of making the workflow of the inter- viewees more efficient. However, ornament as skeuomorphism might 
not equate to efficiency for the user, given that Spiliotopoulos et al. (2018: 18) note that it holds up expert users so that they cannot complete tasks as quickly: 'flat design demonstrates with statistical significance that it allows expert users to execute their task faster'. This point is provocative in relation to illustration, as the concept of usability may take shape differently in illustration. For example, efficiency might not be where illustra- tion's strength lies, and the concept might not encompass the complexity of many enjoyable examples of illustration. Jay's earlier point about noise equating to'more stuff for the eye to look at'suggests that what is a failure in UX terms (slowing down the completion of tasks due to inefficient communica- tion) is a success in illustration (where the eye is encouraged to wander around). Harry Tennant's comments link his added visual noise to the disruption of communication, which can be described as semiotic 'noise' in the transmission between sender and receiver, being 'distortion or alteration in the meaning or method of transmission of a message, whether intended or not' as Sean Hall (2007: 28) describes it. In this respect Tennant commented that by offering a richly ornamented surface he was 'trying to delay the thought of what this illustration is about, maybe making it a bit more open to interpretation'. Therefore Tennant is giving the viewer communicative inefficiency, in order to slow them down: 'hopefully when someone's viewing that image it's like throwing a little curveball in it, in a way. There's an idea in it but I want you to look at the illustration for a bit longer'. This strategy exploits the 'overwhelming' nature of skeuomorphic ornamentation found in Spiliotopoulos et al.'s study, which takes a similar approach to time as found in Twemlow's article. Twemlow quotes Louise Shouwenberg to make the link between the handcrafted and slowing down the viewer:

Freed from its negative connotations, craftsmanship can be valued for the psychological effect it exerts on its user: it not only refers to a slower pace, but also implants this deceleration, and the implied attention to detail, into the product. (2005)

Tennant's work shows how this deceleration can be put into practice, and he goes on to outline the benefits of this in the context of editorial illustration where the image's role is just one part of a greater multimodal text:

In the context of editorial illustration, it's kind of there for you to be reading an article and reflecting on it while you're looking at the illustration. So it promotes some other more lateral thought about an article. If an illustration is doing that then that's a good thing.

The multimodal quality of the text allows illustration this freedom from communicative efficiency, which in turn brings out its strength as imaginative provocation according to Tennant: 'whether you're reading or listening you've got this other thing [...] you're simultaneously looking at this picture, and it's promoting some kind of different thought that you wouldn't have had otherwise'. 
Therefore Tennant is aiming to allow time for contemplation through presenting the viewer with deliberately 'noisy' iconic messages. This relates to the Hick-Hyman Law (HHL) (as it is interpreted within User Experience Design), but here it is configured as a positive. Writing from within the field of psychology, Wifall et al. (2016) summarize the HHL arising from studies by William Edmund Hick and Ray Hyman in the early 1950s: '[it] describes one of the core phenomena in the study of human information processing: mean response time is a linear function of average uncertainty' (Wifall et al. 2016: 555) ${ }^{i}$. The authors explain the current understanding of the $\mathrm{HHL}$ as one that encompasses the difficulty in recognizing the stimulus and also the complexity of the following task (Wifall et al. 2016: 564), meaning that when translated into UX design guidelines it becomes the following maxim: 'the time it takes to make a decision increases proportionally to the number and complexity of choices' (U.S. Department of Health \& Human Services 2019). This phenomenon relates to Tennant offering visual complexity to slow down the reader who is trying to resolve the information in front of them into something meaningful to them. However, it is deliberately contrary to the clarity and efficiency usually prioritized when designing a user's route through an experience, raising the question of whether there is something disruptive or subversive about filling images up to the brim with rich textures and additional marks.

\section{Subversive scribbling}

Jay demonstrates an oppositional approach to his visual environment when stating'when everything is flat it's nice to have something opposed to that', showing this to be a calculated aesthetic decision. If the specificity of the marks employed by the interviewees is explored further, the scribbles in Tennant's work become particularly useful for analysing the benefits of noise. These can be seen in Figure 3 and are an established trope in contemporary illustration, appearing in work by luminaries such as Michelle Thompson and Alex Williamson as well as those who admire them (as I do). In contrast to the aesthetically aware design decisions of said illustrators, the British art critic Herbert Read specifically targeted scribbling when he wrote in 1935 of ornament as a psychological need, describing it as an 'ineradicable feeling', and a primal urge to fill blank spaces - whether it be scribbling on a blotting pad or a toilet wall. He uses the Latin term horror vacui to describe this, explain- ing it as 'the incapacity to tolerate an empty space'. Read does not argue for eradicating such a practice, but he does claim that the instinct behind it is 'not essentially aesthetic' (1935: 23).

Jay recognized the urge to fill empty spaces that Read proposes, but he and Tennant execute the act in an aesthetically considered way. Therefore Read's claim that filling empty space with visual noise is divorced from aesthetic concerns is not wholly convincing. On the basis of the interviews conducted it appears that horror vacui can be driven by an aesthetic instinct, with Jay and Tennant's comments leading me to propose that the governing principles emerging are generosity and temporality. Also explored previously is the utility of ornament as disruptive, giving it potential as a critical strategy and therefore situating illustrators alongside a history of creative practitioners who use their practice critically. These include (but are not limited to) Robert Rauschenberg with his Erased de Kooning Drawing of 1953, Gustav Metzger's autodestructive art (in particular his acid action painting of 1960) and, more recently, Edward Fella's deconstruction within graphic design. Fella says of his engagement with critical theory through his practice, 'Deconstruction is a way of exposing the glue that holds 
together western culture'(Meggs and Purvis 2012: 535), pinpointing the strategy common to all of these examples of bringing the surface of the image to the viewer's atten-tion, in order to question or disrupt established practices and structures. This strategy is in keeping with Twemlow's point that ornament and decoration can give designers alternative ways of imagin- ing the purpose of design, and beyond this they'can be used as framing devices or carriers for critical or narrative commentary', noting that Daniël van der Velden of Metahaven suggests that a lean Modernist visual language is not the best tool for expressing this (2005).

Jay suggests that his visual noise is deliberately disruptive to the context for the image, which for his work is often the magazine or newspaper page either online or in printed form. Keith Robertson dissects the semiotic values of magazine layouts, offering an insight into the setting for Jay's work. Robertson proposes that they are divided between the elite (such as Vogue) and the mass market, as exemplified by That's Life! Robertson sees the former adopting the modernist grid for its layout, and this category is more clearly aligned with the context for Jay's work than the mass market publications he discusses. Robertson suggests that elite publications are exclusive due to their role in policing the social divisions represented by audience stratification. In contrast, he argues favourably for the visu- ally busy, cluttered 'Sh*t Design' of popular magazines, for it is able to disrupt the snobby white space that is a feature of the more 'upmarket' publications (2002). Articulated using these terms, the noisy surface of illustration challenges the modernist grid and everything else Robertson sees it standing for in the same way as 'Sh*t Design'. Surface noise can therefore be cast as the 'visual ideology' described by Nicos Hadjinicolao and paraphrased by Phil Sawdon in relation to drawing style:

It is a specific combination of the formal and thematic elements of a picture through which people express the ways they relate their lives to the conditions of their existence, a combina- tion that constitutes a particular form of the overall ideology of a social class.

(2005: 74)

In the examples of Jay and Tennant, the formal elements they have selected to combine with the thematic elements given by a commission can be read as a comment on the conditions of the illus- trator's existence, in particular the complicated relationship between the illustration workplace and digital technology, and how unfulfilling that can be. By making these choices and comments the theme emerging from the two interviewees is that we still need some respite from digital technology, both as makers and also as the viewers increasingly encountering these images on screen. Therefore I'm proposing that both Jay and Tennant's work reformulates Loos' point about ornament being wasted time to instead harness ornament as the solution. They both use the ornamentation of the image to reconfigure the image production process in favour of methods that allow them to find joy in their work.

\section{What now for ornament?}

Twemlow states that the slightly dystopian ornament of which she writes is'particular to the time we live in'; Hadjinicolao suggests all stylistic decisions such as ornament are representative of their circumstances. The work of the interviewees has offered us 
particular insights related to the pres- sures of the creative industries of the time it was produced within. Can we extrapolate further, as Morris or Loos might? Does it cast our contemporary society as savage or decadent, as Herbert Read saw go hand in hand with decoration? Similarly, Philip Meggs summarizes the postmodern use of ornament in graphic design of the 1980 s as decadent and superficial, stating:

In a decade when economic expansion and materialism were fueled by abundant energy supplies and heavily leveraged debt, [...] Graphic designers used lush palettes and orna- mented their work with gestures, textures, and decorative geometric elements. Surface and style often became ends in themselves.

(Meggs and Purvis 2012: 475)

The work of Tennant and Jay could be seen as an extension of the postmodern gesture and texture Meggs describes, but their use of ornament has been shown to be neither superficial as per Meggs' terms nor deliberately useless in the reactionary response to Modernism that Twemlow notes (2005). Without undertaking an exhaustive survey of a wider range of examples I would not like to overstretch the interpretive possibilities offered by some scribbles in an editorial illustration, or make too grand a claim as to the generous, temporal and critical impetus behind them. That said, I hope that this article has traced the theme of slowing viewers down through applying ornamen- tal analogue noise to images, in order to enrich their experience of illustration. Furthermore, by framing ornament as labour, this article sought to expand the discussion of joy within the produc- tion of illustration, and also of ornament's role in enmeshing illustrators in the circular economy. As a proposal for future practical experiments, this article makes an argument for the potential use of ornament as a tool within critical illustration practice. The illustrators interviewed for this article have offered the first steps in this regard; by creating a considered response to the designed context illustration exists within, with their work providing a counterpoint to the discourse

surrounding its context and offering insights into the illustration industry it is a product of. The positive outcome of this article's analysis of Jay and Tennant's working processes is that they demonstrate the illustrator's ability to retain joy in working, through taking a problem and making it into the solution by nimbly synthesizing a modernist production strategy with a postmodern critical edge.

\section{References}

Conrads, U. (ed.) (1971), Programs and Manifestos on 20th-Century Architecture, Cambridge, MA: MIT Press.

Ellen MacArthur Foundation (2017), 'A new textiles economy: Redesigning fashion's future', https:// www.ellenmacarthurfoundation.org/assets/downloads/publications/A-New-

Textiles-Economy Full-Report Updated 1-12-17.pdf. Accessed 1 August 2019.

Hall, S. (2007), This Means That: A User's Guide to Semiotics, London: Laurence King. Meggs, P. B. and Purvis, A. W. (2012), History of Graphic Design, 5th ed., Hoboken, NJ: Wiley. Pevsner, N. (1960), Pioneers of Modern Design, Harmondsworth: Penguin. Read, H. (1935), Art and Industry, New York: Harcourt, Brace and Company. Robertson, K. (2002), 'Sh*t design: An exploration of the aesthetic in graphic design', 10th Sights, Minds and Matters Lecture Series, RMIT University, Melbourne, 8 October. 
Sawdon, P. J. (2005), 'What shall I draw? Just a few words', in L. Duff and J. Davies (eds), Drawing - The Process, Bristol: Intellect, pp. 69-81.

Slade, G. (2006), Made To Break: Technology and Obsolescence in America, Cambridge: MA: Harvard University Press.

Spiliotopoulos, K., Rigou, M. and Sirmakessis, S. (2018), 'A comparative study of skeuomorphic and flat design from a UX perspective', Multimodal Technologies and Interaction, 2:2, article 31, https:// doi.org/10.3390/mti2020031. Accessed 30 October 2019.

Twemlow, A. (2005), 'The decriminalisation of ornament', Eye Magazine, Winter, http:// www.eyemagazine.com/feature/article/the-decriminalisation-of-ornament-full-text.

Accessed 20 May 2018.

Wifall, T., Hazeltine, E. and Toby Mordkoff, J. (2016), 'The roles of stimulus and response uncertainty in forced-choice performance: An amendment to Hick/Hyman Law', Psychological Research, 80:4, pp. 555-65.

US Department of Health \& Human Services (2019), 'What \& why of usability: Glossary', https:// www.usability.gov/what-and-why/glossary/a/index.html. Accessed 30 July 2019.

\section{Suggested citation}

Black, S. (2019), 'Fibs and fripperies: References to the real in digital illustration', Journal of Illustration,

6:2, pp. 289-304, doi: 10.1386/jill_00015_1

\section{contributor details}

Stephanie Black is an academic, researcher and illustrator. She has a Ph.D. from University of the West of England, Bristol, focusing on practice-led-research methods and how the concept of time is a quality of illustration. She has spoken at conferences and exhibited work internationally, and has worked on collaborative music projects combining drawing, film, and animation. She is also co-editor of $H A T C H$, a drawing research project.

Contact: Room 113 Roland Levinsky Building, Plymouth University, Faculty of Arts, Drake Circus, Plymouth, PL4 8AA, UK.

E-mail: stephanie.black@plymouth.ac.uk https://orcid.org/0000-0001-8248-6662

Stephanie Black has asserted her right under the Copyright, Designs and Patents Act, 1988, to be identified as the author of this work in the format that was submitted to Intellect Ltd. 
'Wifall et al. conclude that both stimulus uncertainty and response uncertainty result in longer decision making, both modifying

the original HHLs focus on stimulus uncertainty, and also making it relevant

to the discussion of tasks associated

with skeuomorphic design. However, the applicability of the HHL to User

Experience Design may be slightly less clear with each modification of its principles

due to the design of the experiments undertaken, and therefore caution should

be exercised before applying its principles casually.

It may not be as simple as presuming that a multimodal experimental design

that maps visual stimuli to vocal responses

(as Wifall et al. do) results in findings that are transferrable to

a complicated real- world communication process, or one that takes place entirely visually. 